\title{
Studies on Antimicrobial Activity and Phytochemical Profile of Mangifera Indica Leaf Extract
}

\author{
Rajendra Prasad Bharti \\ Department of Environmental Biology \& Biotechnology A.P.S. University Rewa (MP) 486003
}

\begin{abstract}
The present study deals with Studies on antimicrobial activity and photochemical profiles of Mangifera Indica (kottukonamvarika) leaf extract. The leaf of mangifera indica; studies with the aim of determined the following photochemical parameters for these species microscopial characters. Leaf contents, photochemical content, about 6 extract (methanol, acetone, hexane, ethyl acetate, hexane-ethyl acetate, aqueous extraction) from the leaves of Mangifera indica was extracted. Hexane-ethyl acetate was characterized by Gas Chromatography-Mass Spectroscopy. The antimicrobial activity of different extract was tested against human and plant pathogenic bacteria. Hexane-ethyl acetate extract showed significant role on inhibiting almost all tested pathogenic organisms.
\end{abstract}

\section{Introduction:}

The plant materials were collected from the village dihiya (District Rewa m.p.). In the month of January 2013. The plant was identified by local people of that village; A herbarium specimen of the plant was preserved in the Department of Environmental biology in Biotechnology Lab from APS University Rewa m.p. of our Institute for reference. The leaves use of medicinal plants as herbal remedies to prevent and cure several ailments differs from community to community Traditionally used medicinal plants have recently attracted the attention of the biological scientific communities. This has involved the isolation and identification of secondary metabolites produced by plants and their use as active principles in medicinal preparations plants have limitless ability to synthesize aromatic secondary metabolites, most of which are phenols or their oxygen-substituted derivatives. Extraction methods involve separation of medicinally active fractions of plant tissue from inactive/inert components by using selective solvents and extraction technology. Solvents diffuse into the solid plant tissues and solubilize compounds of similar polarity. Mango (Mangifera indica L.) is one of the most important tropical plants in the world. It grows in the tropical and subtropical regions and its parts are commonly used in folk medicine for a wide variety of remedies. Many phenolic compounds have been detected in mango peels mango bark 8, mango puree concentrate mango pulps and seed kernels. Several pharmacological activities of mango extracts have been reported including anti-inflammatory 6 , antioxidant antiallergic and antihelmintic and antiamoebic. In the present study, certain works such as phyto-chemical characterization, antimicrobial activity of extract, histochemical studies, and cytotoxic effects of hexane-ethyl acetate extract against cell lines.

\section{Materials And Methods:- Plant Materials :-}

The plant material leaves of Mangifera indica (Kottukonam varikka) was collected from tropical area from the village of Dihya (District Rewa m.p.) In the month of January 2013. The plant was identified by local people of that village and authenticated by Dr. U. K. Chauhan, Professor, of Biotechnology, APSU Rewa; A herbarium specimen of the plant was preserved in the Department of Environmental biology and biotechnology APS University Rewa (MP) of our Institute for further reference. The leaves were separated and dried under shade, pulverized by mechanical grinder, passed through 40 mesh sieves and stored in a closed vessel for further use. All the reagents used were of analytical grade obtained from Pinnacle Biomedical Research institute (PBRI). Bharat Scout and Guide Campus (Near Regional Science Centre) Shanti Marg, Shayamla hills Bhopal (m.p.) India 462003. The macroscopical characters (size, shape, colour, odour, taste, surface, texture, venation, margin, base, and petiole) of the leaves were observed. Then, for powder microscopical study, the powder was stained with phloroglucinol and concentrated $\mathrm{HCl}$ to study the lignified cells, lignified parenchyma, trichomes, fibers, xylem vessels, mesophyll, palisade cells and stomata, etc. The powder was also stained with N/50 iodine solution to detect the presence of starch. A small portion of powder was mounted in water to identify calcium oxalate crystals 11 . Quantitative microscopy was determined by methods prescribed by Trease and Evans 12 . The ash values, alcohol soluble and water soluble extractives values and Loss on drying of leaves were determined as per the Indian Pharmacopoeia methods.13 The crude fiber content was done by Dutch process.14 The behavior of the powdered leaves with different chemical reagents was studied.15 The fluorescence characters of the various extracts and powdered leaf with different chemical reagents were observed under day light and UV light $(254 \mathrm{~nm} \& 366 \mathrm{~nm})$, by following procedure reported by Kokoshi et al.16 Measurements of the cells/ tissues 
were made with the help of micrometer under a compound microscope.17 Other extractive values were determined successively starting from petroleum ether $\left(60-80^{\circ}\right)$, chloroform, acetone, ethyl acetate, methanol and distilled water by using sox let extraction apparatus.18 For this purpose the powder (100g ) was successively hot extracted with $300 \mathrm{ml}$ of above solvents for $72 \mathrm{~h}$. Before switching over to the next solvent, the powder under extraction (marc) was dried to remove the traces of earlier solvent. The dried extractives were obtained after evaporation of solvent under reduced pressure. The angle of repose of powder was determined by the funnel method. The accurately weighed powder was taken in a funnel. The height of the funnel was adjusted in such a way that the tip of the funnel just touched the apex of the heap of the powders. The powder was allowed to flow through the funnel freely onto the surface. The diameter of the powder cone was measured and angle of repose was calculated using the following equation, Tan $q=h / r$, Where $h$ and $r$ are the height and radius of the powder cone. 19 For the determination of bulk density, $2 \mathrm{~g}$ of powder, previously lightly shaken to break any agglomerates formed, was introduced into a $10 \mathrm{ml}$, measuring cylinder. After the initial volume was observed, the cylinder was allowed to fall under its own weight onto a hard surface from the height of $2.5 \mathrm{~cm}$ at 2 seconds intervals. The tapping was continued until no further change in volume was noted. Bulk density was calculated for dried powdered drug using following formula: Bulk Density = Mass of Powder/ Bulk volume.20 Preliminary phytochemical tests of different extracts were performed by using specific reagents through standard procedures.21-25 (Figure 1, 2 ).

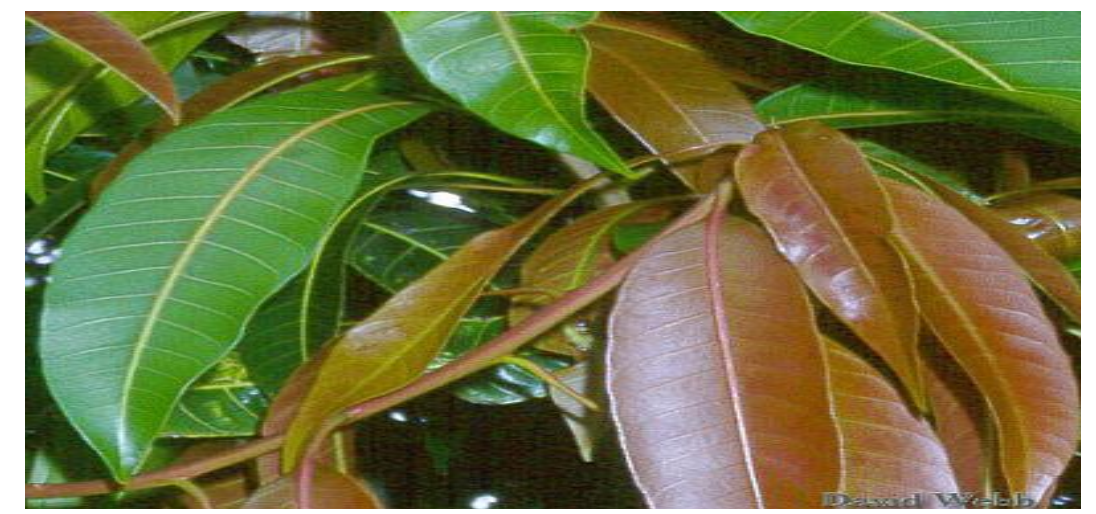

FIGURE 1: MANGO LEAF

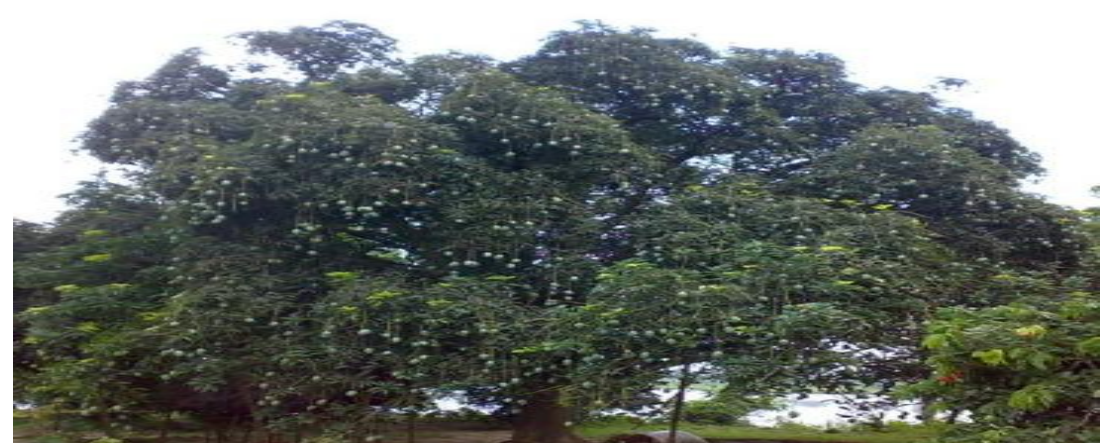

FIGURE 2: MANGIFERA INDICA TREE

Histochemical Studies:- For Fluorescence microscopy and histochemical works, fresh plant materials are collected and serial hand sections were produced. To this thin hand sections specific fluorescent and histochemical reagents were added and observed under the fluorescent microscope. By the appearance of specific colour change of storage and cellular chemicals, the presence of various histochemicals will be identified. The histochemical reagent such as Phloroglucinol-HCl, Dragendorff reagent was used for the localization of lignin and alkaloids respectively.

\section{Results And Discussion:-}

In the present study, an amount of 500gm of Mangifera indica leaf and solvents such as methanol, acetone, hexane, ethyl acetate, hexane-ethyl acetate and water were used for the extraction. From each sample, $\sim 10 \mathrm{ml}$ extracts were collected. In this $20 \%$ was the yield of methanol, acetone, hexane, ethyl acetate, hexaneethyl acetate and aqueous extract of leaf.

Analysis of Hexane-ethyl acetate extract: - Analysis indicated that the hexane-ethyl acetate extract contained about 10 peaks. The composition of hexane-ethyl acetate extract and its relative percentages are given in Table 
1. Terpinyl acetate (5.80\%) and phytol isomer $(5.12 \%)$ are as the major constituents and this leaf extract contains the minor constituents like oxirane (3.57\%), sabinene (3.24\%), beta-pinen (3.34\%), beta-myrcene (3.23\%), cymene (3.68\%), alpha-limonene (2.82\%), eucalyptol (1,8-cineo (4.71\%), 1,3-benzodioxole, 5-(2-, (3.68\%). The phenolic profile of ethyl acetate fraction of mango leaves and a total of 8 compounds including benzoic acid, pyrogallol, p-hydroxybenzoic acid, vanillic acid, syringic acid ferulic acid, ethyl gallate and Gallic acid were tentatively identified on the basis of spectral data and standard chemicals. The composition of Mangifera indica hexane-ethyl acetate and its relative percentages are given in Table 1 and Figure 3. TABLE 1: PERCENTAGE, COMPOSITION OF MANGIFERA INDICA HEXANE-ETHYL ACETATE EXTRACT:-

\begin{tabular}{|c|l|l|l|}
\hline Number of Peaks & $\begin{array}{l}\text { Retention Time (minutes) } \\
8.907\end{array}$ & Compounds & $\begin{array}{l}\text { Abundance (\%) } \\
\text { Oxirane }\end{array}$ \\
2 & 9.022 & Sabinene & 3.57 \\
3 & 9.514 & Beta-pinen & 3.34 \\
4 & 10.758 & Beta-myrcene & 3.23 \\
5 & 10.896 & Cymene & 3.68 \\
6 & 11.037 & Alpha-limonene Eucalyptol & 2.82 \\
7 & 20.222 & (1,8-cineo 1,3-Benzodioxole, & 4.71 \\
8 & 22.433 & (2-Terpinyl acetate & 3.68 \\
9 & 49.350 & Phytol isomer & 5.80 \\
10 & 51.647 & & 5.12 \\
\hline
\end{tabular}

\section{Antimicrobial activity of leaf extract of Mangifera indica: -}

In the present study, the antimicrobial activity of different extract of Mangifera indica was tested against nine bacteria (Salmonella typhi, Klebsiella pneumoniae, Enterobacter aerogens, Mycobacterium tuberculosis, Streptococcus pyrogens, Pseudomonas aeuroginosa, Proteus vulgaris, Escherichia coli, and Staphylococcus aureus). In antimicrobial activity, the methanol extract showed maximum zone of inhibition against Entrobacter aerogens $(1.3 \mathrm{~cm})$. The acetone extract showed a maximum zone of inhibition against Salmonella typhi $(3.0 \mathrm{~cm})$. The hexane extract showed maximum zone of inhibition against Mycobacterium tuberculosis $(0.5 \mathrm{~cm})$. The ethyl acetate extract showed maximum zone of inhibition against Enterobacter aerogens $(1.9 \mathrm{~cm})$. The hexane-ethyl acetate extract showed maximum zone of inhibition against Streptococcus pyrogens $(2.6 \mathrm{~cm})$ and also against Salmonella typhi $(2.5 \mathrm{~cm})$. It was clear from the present results, that hexaneethyl acetate extract exhibited pronounced activity against all the tested bacteria. The presence of phytoconstituents in the leaf extracts may be responsible for the antibacterial activity of the plant. It has been documented that different solvents have diverse solubility capacities for different phytoconstituents 20 . The difference in activities among the solvents recorded in this study may be associated with the presence of oils, wax, resins, fatty acids or pigments, which had been reported to be capable of blocking the active ingredients in the plant extract, thus, preventing the plant extract from accessing the bacterial cell wall 21 . The result was represented in table 2.

Table 2: Antimicrobial activity of Mangifera indica leaf extract against 9 bacterial strains by Kirby Bauer method

\begin{tabular}{|c|c|c|c|c|c|c|}
\hline Microorganisms & \multicolumn{4}{|c|}{ Zone of inhibition in $10 \mu \mathrm{l}$ sample $(\mathrm{cm})$} & \multirow[b]{2}{*}{$\begin{array}{l}\text { Hexane ethyl acetate } \\
\text { extract }\end{array}$} & \multirow[b]{2}{*}{$\begin{array}{l}\text { Aqueous } \\
\text { extract }\end{array}$} \\
\hline Methanol extract & Acetone & extract & $\begin{array}{l}\text { Hexane } \\
\text { extract }\end{array}$ & Ethyl acetate extract & & \\
\hline Salmonella typhi & 0.9 & 3.0 & 0.1 & 1.6 & 2.5 & 0.2 \\
\hline Klebsiella pneumoniae & 1.0 & 1.2 & 0.3 & 1.4 & 1.4 & 0.3 \\
\hline Enterobacter aerogens & 1.3 & 1.2 & 0.1 & 1.9 & 1.5 & 0.2 \\
\hline Mycobacterium & 0.3 & 1.3 & 0.5 & 1.2 & 1.0 & 0.1 \\
\hline tuberculosis Streptococcus & 1.0 & 2.2 & 0.5 & 1.1 & 2.6 & 0.3 \\
\hline pyrogens Pseudomonas & 0.2 & 1.1 & 0.2 & 1.4 & 1.4 & 0 \\
\hline aeuroginsa & 0.8 & 1.0 & 0.1 & 1.3 & 1.6 & 0.2 \\
\hline vulgaris & 0.6 & 1.4 & 0.1 & 1.0 & 1.7 & 0.3 \\
\hline $\begin{array}{l}\text { Escherichia coli } \\
\text { Staphylococcus aureus }\end{array}$ & 0.6 & 1.9 & 0 & 1.3 & 0.6 & 0.6 \\
\hline
\end{tabular}

\section{Histochemical analysis:-}

The stains localize specific histochemicals. Localizations include lignin content and alkaloids (Figure $4,5)$. In general, parenchymatous cells showed less amount of lignin because infection with any pathogenic agent might have delayed the process of lignification in cortical and pericycle region. 


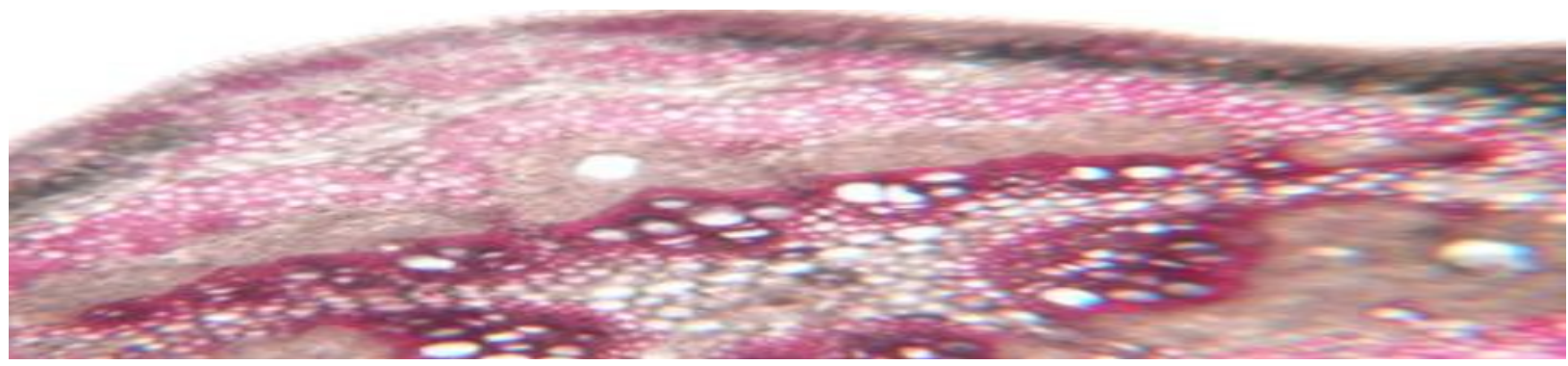

FIGURE 4: LOCALIZATION OF LIGNIN CONTENT

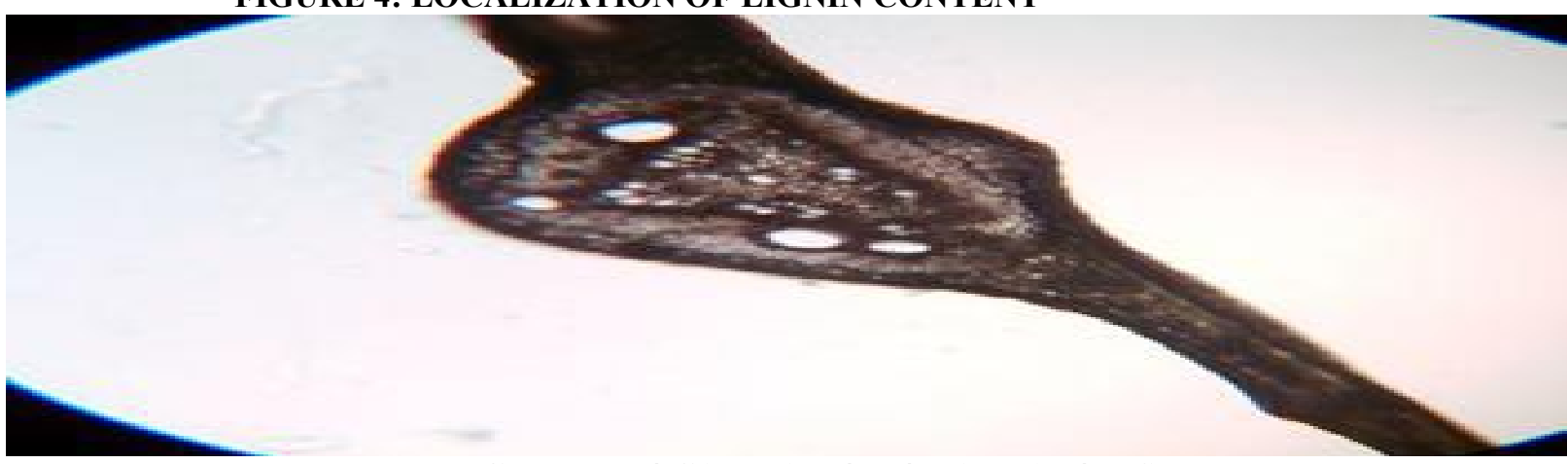

\section{FIGURE 5: LOCALIZATION OF ALKALOIDS}

\section{Conclusion:-}

From this study it can be concluded that the hexane-ethyl acetate leaf extract of Mangifera indica exhibited pronounced activity against all the tested bacteria. The presence of phytoconstituents in the leaf extracts may be responsible for the antimicrobial activity. The use of medicinal plants to cure diseases has been extensively applied by people. Data from the literature as well as our results reveal the great potential of plants for the therapeutic treatment and have not been completely investigated. Additional studies would be needed further to evaluate the potential of this leaf extract as antimicrobial agents.

\section{References: -}

[1]. Kubmarawa D, Ajoku GA, Enwerem NM, Okorie DA: Preliminary phytochemical and antimicrobial screening of 50 medicinal plants from Nigeria. Afri J Biotechnology 2007; 6: 90- 1696.

[2]. Taylor JLS, Rabe T, McGraw LJ, Jager AK, van Staden J: Towards the scientific validation of traditional medicinal plants. Plant Growth Regul 2001; 34: 23-37.

[3]. Geissman TA: Flavonoid Compounds, Tannins, Lignins and Related Compounds, Elsevier, New York, Vol. 9, $1963: 265$.

[4]. Green RJ: Antioxidant Activity of Peanut Plant Tissues. Masters Thesis, North Carolina State University, USA, 2004.

[5]. Severi JA, Lima ZP, Kushima H, Brito ARMS, Dos Santos LC, Vilegas W, Hiruma-Lima CA: Polyphenols with antiulcerogenic action from aqueous decoction of mango leaves (Mangifera indica L.). Molecules 2009; 14: 1098-1110.

[6]. Garrido G, Gonzalez D, Lemus Y, Garcia D, Lodeiro L, Quintero G, Delporte C, Nunez Selles AJ and Delgado R: Invivo and in vitro anti-inflammatory activity of Mangifera in

[7]. Schieber A, Beaardini N and Carle R: Identification of flavonol and xanthone glycosides from mango (Mangifera indica L.) peels by high-performance liquid chromatography-electrospray ionization mass spectrometry. J Agric Food Chem 2003; 51: 5006-5011.

[8]. Nong C, He W, Fleming D, Pan L and Huang H: Capillary electrophoresis analysis of mangiferin extracted from Mangifera indica L. bark and Mangifera persiciformis. J Chromatogr B 2005; 826: 226-231.

[9]. Schieber A, Ullrich W and Carle R: Characterization of polyphenols in mango puree concentrates by HPLC with diode array and mass spectrometric detection. Innov Food Sci Emerg 2000; 1: 161-166.

[10]. Ribeiro SMR, Barbosa LCA, Queiroz JH, Knodler M and Schieber A: Phenolic compounds amd antioxidant capacity of Brazilian mango (Mangifera indica L.) varieties. Food Chem. 2008; 110: 620-626.

[11]. Maisuthisakul P and Gordan MH: Antioxidant and tyrosinase inhibitory activity of mango seed kernel by product. Food Chem. 2009; 117: 332-341.

[12]. Garcia D, Escalante M, Delgado R, and Ubeira FM, Leiro J: Anthelminthic and antiallergic activities of Mangifera indica L. stem bark components Vimang and mangiferin. Phytother Res 2003; 17: 1203-1208.

[13]. Tona L, Kambu K, Ngimbi N, Cimanga K and Vlietinck AJ: Antiamoebic and phytochemical screening of some Congolese medicinal plants. J Ethnopharmacol 1998; 61: 57-65.

[14]. Morris JA, Khettry A and Seitz EW: Antimicrobial activity of aroma chemicals and essential oils. Journal of the American oil Chemist's Society 1979; 56: 595-603.

[15]. Ross SA, El-Keltawi NE, Megalla SE: Antimicrobial activity of Egyptian aromatic plants. Fitoterapia 1980; 51: 201-205

[16]. Yousef RT, Tawil GG: Antimicrobial activity of volatile oils. Pharmazie 1980; 35 (11): 698-701.

[17]. Deans SG and Ritchie G: Antibacterial properties of plant essential oils. International Journal of Food Microbiology 1987; 5: 165180 .

[18]. Hili P, Evans CS, and Veness RG: Antimicrobial action of essential oils: The effect of dimethylsulfoxide on the activity of cinnamon oil. Letters in Applied Microbiology 1997; 24: 269-275. 
[19]. Abdelnaser Abdelghany Elzaawely and Shinkichi Tawata; Preliminary phytochemical investigation on Mango (Mangifera indica L.) leaves. World Journal of Agricultural Sciences 2010; 6: 735-739.

[20]. Marjorie MC: Plant products as antimicrobial agents. Clin Microbiol Rev 1999; 12: 564-582.

[21]. Jigna P, Nehal K, Sumitra C: Evaluation of antibacterial and phytochemical analysis of Bauhinia variegates L. bark. Afri J Biomed Res 2006; 9: 53-56.

[22]. Darling HM, Faulknes IR and Wallendal: Culturing the potato root nematode. Phytopath 1957; 47: 70.

[23]. Muanza DN, Euler KL, Williams L, Newman DJ: Screening for antitumor and anti-HIV activities of nine medicinal plants from Zaire. Int. J Pharmacol 1995; 33: 98. 